\title{
DEVELOPMENT AND VALIDATION OF A HIGH-PERFORMANCE LIQUID CHROMATOGRAPHY METHOD FOR DETERMINING METFORMIN HYDROCHLORIDE IN DRIED BLOOD SPOTS
}

\author{
YAHDIANA HARAHAP*, PRASTIWI ARUM SARI, CATUR JATMIKA \\ Bioavailability and Bioequivalence Laboratory, Faculty of Pharmacy, Universitas Indonesia, Depok, 16424, Indonesia. \\ Email: yahdiana03@yahoo.com \\ Received: 08 June 2018, Revised and Accepted: 09 August 2018
}

ABSTRACT

Objective: This study aimed to develop an analytical method for determining metformin concentrations in human dried blood spots (DBS) using optimal chromatographic conditions and DBS preparation methods and validate the analytical methods.

Methods: Analysis metformin $\mathrm{HCl}$ performed using C-18 columns ( $250 \mathrm{~mm} \times 4.6 \mathrm{~mm})$ at a column temperature of $40^{\circ} \mathrm{C}$ with a mobile phase acetonitrile phosphate buffer $(40: 60 \% \mathrm{v} / \mathrm{v})$ at pH 7.0 using a flow rate of $0.8 \mathrm{~mL} / \mathrm{min}$, a photodiode array detector at a wavelength of $234 \mathrm{~nm}$, and atorvastatin calcium as an internal standard. Samples were prepared by protein precipitation with $60 \%$ methanol and then drying using nitrogen gas at $60^{\circ} \mathrm{C}$ for 15 min before reconstituting in $200 \mu \mathrm{L}$ of the mobile phase.

Results: Invalidation procedures, the present methods met the acceptance criteria stated in the EMEA Bioanalytical Guideline 2011. The method was also linear at the concentration range of $25.0-5000.0 \mathrm{ng} / \mathrm{mL}(\mathrm{r}=0.9997)$.

Conclusion: The developed method for determination of metformin $\mathrm{HCl}$ in DBS sample was valid with a concentration range of $25.0-5000.0$ ng/mL and can be applied to in vivo studies.

Keywords: Metformin, High-performance liquid chromatography, Optimization, Validation, Dried blood spot.

(C) 2018 The Authors. Published by Innovare Academic Sciences Pvt Ltd. This is an open access article under the CC BY license (http://creativecommons. org/licenses/by/4. 0/) DOI: http://dx.doi.org/10.22159/ijap.2018.v10s1.26

\section{INTRODUCTION}

In 2012, diabetes caused 1.5 million deaths globally, and high glucose levels contributed to 2.2 million deaths by increasing the risk of cardiovascular diseases and other disorders. Among these 3.7 million deaths, $43 \%$ were of people $<70$ years old and were considered premature. In Indonesia, premature deaths account for 48,300 of 99,400 diabetes-related deaths annually [1].

Metformin is a biguanide medicine that lowers glucose levels by reducing hepatic glucose production and intestinal glucose absorption. Metformin is the most prescribed drug for type 2 diabetes and is the drug of choice for diabetes patients with obesity [2]. Metformin is also present in the List of National Essential Medicines according to the Indonesian Ministry of Health. Hence, metformin is the most needed medicine and must be made available at all health facilities.

Pharmacokinetics studies can be performed using plasma, serum, or whole blood, although most studies are performed with plasma or serum samples because these are easy to prepare. However, the use of these two matrices requires the inconvenient collection of blood samples from patients. In the past few years, a new sampling method has been developed using dried blood spot (DBS) samples on filter paper. Such DBS methods offer improved convenience for patients because they require a small volume of blood [3]. Therefore, DBS methods may facilitate the implementation of pharmacokinetics or bioequivalence $(\mathrm{BE})$ tests for metformin and other medicines because blood sampling is minimal and does not require the imposition of deep wounds with the entry of needles or catheters [4].

Analyzes of metformin in DBS samples will require high selectivity and sensitivity due to minimal amounts of blood collected from peripheral sites. Some high-performance liquid chromatography (HPLC) methods have been developed for analyzes of DBS samples. HPLC is also commonly available in laboratories and is applicable to $\mathrm{BE}$ and other clinical tests. Since HPLC can be combined with various detectors, its uses can be adjusted to suit available tools. Herein, we used photodiode array (PDA) detectors that can perform rapid analyzes at several wavelengths [2].

In drug compound analyses, sample preparation is the most important part. Thus, extraction from DBS samples was conducted and extracts were dissolved in the mobile phase. To optimize the results, protein precipitation was performed, and we used a polar solvent to accommodate the polar properties of metformin, as shown in previous analyzes using HPLC methods [2]

Quantitative analyzes were performed using an internal standard with the similar chemical properties as the analyte, and this was added to samples with as yet unknown concentrations of analyte. In previous analyzes of metformin, diazepam, phenformin $\mathrm{HCl}$, salbutamol, calcium atorvastatin, and ranitidine $\mathrm{HCl}$ were used as internal standards. In this study, we used calcium atorvastatin because it has a similar retention time to that of metformin $\mathrm{HCl}$, is readily available, and can be used with a known and validated correction factor to determine analyte concentrations in unknown samples [5].

The methods used herein were modified from the reverse phase HPLC procedures reported by AbuRuz et al., in 2006, and were optimized for determinations of metformin $\mathrm{HCl}$ in DBS. After selecting optimal conditions, then validated the method based on the Bioanalytical Guidelines of the European Medicines Agency (EMEA; 2011) [6]. Measured parameters included selectivity, linearity, accuracy, precision, stability, recovery, and carry-over. The methods developed herein are expected to be used in pharmacokinetics tests, BE tests, and in other clinical tests of diabetic patients receiving metformin $\mathrm{HCl}$ therapy. 


\section{MATERIALS AND METHODS}

\section{Materials}

Metformin $\mathrm{HCl}$ and calcium atorvastatin were purchased from British Pharmacopoeia (BP), orthophosphoric acid (Merck), HPLC grade methanol (Merck), sodium dihydrogen phosphate (Merck), acetonitrile (Merck), Aquabidestilata (Ikapharmindo), filter paper (Perkin Elmer), human blood (Indonesian Red Cross Society), Instrumentation HPLC, a C-18 column (Waters, SunFire ${ }^{\mathrm{TM}} 5 \mu \mathrm{m} ; 250 \times 4.6 \mathrm{~mm}$ ), and a PDA detector (Waters 2996).

\section{Standard solution}

Metformin $\mathrm{HCl}$ was carefully weighed to $10.0 \mathrm{mg}$ and was then dissolved with Aquabidestilata sterilized water in $10.0 \mathrm{~mL}$ volumetric flasks to a concentration of $1.0 \mathrm{mg} / \mathrm{mL}$. The internal standard calcium atorvastatin was carefully weighed to $10.0 \mathrm{mg}$ and was then dissolved in methanol in $10.0 \mathrm{~mL}$ volumetric flasks to a concentration of $1.0 \mathrm{mg} / \mathrm{mL}$. Dilutions were then performed to generate solutions with a range of concentrations.

\section{Optimization of chromatographic condition}

Mixtures containing $10.0-\mu \mathrm{g} / \mathrm{mL} \mathrm{HCl}$ metformin and $10.0-\mu \mathrm{g} / \mathrm{mL}$ calcium atorvastatin were injected in 20- $\mu \mathrm{L}$ aliquots into the HPLC instrument and responses were observed. Optimization began with the selection of an optimal wavelength using the PDA detector. Metformin $\mathrm{HCl}$ analyzes were performed using the wavelength maxima at $234 \mathrm{~nm}$. Sodium dodecyl sulfate (SDS) was used to provide ion pairs, and SDS concentrations were optimized at 2, 3, and $10 \mathrm{mM}$. The mobile phase composition and phosphate buffer $\mathrm{pH}$ were then optimized, and the best flow rate was established. To optimize the mobile phase, acetonitrile phosphate buffer ratios of 30:70, $40: 60$, and $35: 65$ were tested with $\mathrm{pH}$ values of $6.0,6.5$, and 7.0. Flow rates were optimized by comparing $0.8,1.0$, and $1.2 \mathrm{~mL} / \mathrm{min}$.

\section{System suitability tests}

After determining optimum conditions for metformin $\mathrm{HCl}$ analysis, mixed solutions of metformin $\mathrm{HCl}$ and internal standard were injected 6 times and coefficients of variation (CV) for retention times and areas under the curve for each substance were then calculated as PAR, which should be $<2.0 \%$.

\section{Optimization of DBS sample preparation}

DBS sample preparation and extraction of metformin $\mathrm{HCl}$ were conducted using the protein precipitation method. Protein precipitation was performed by adding $50 \mu \mathrm{L}$ of $10 \mu \mathrm{g} / \mathrm{mL}$ calcium atorvastatin to DBS samples containing metformin $\mathrm{HCl}$ at a concentration of $1 \mu \mathrm{g} / \mathrm{mL}$. Subsequently, 1.0-mL aliquots of distilled water, $60 \%$ methanol, $95 \%$ methanol, 100\% acetonitrile, and acetonitrile formic acid (90:10) were added to these samples, and selected mixtures were used to optimize volumes of extraction solvent at $0.2,0.5,0.7$, and $1.0 \mathrm{~mL}$. Sonication times were then optimized by comparing samples after 5-, 10-, and 15-min sonication. Finally, the evaporation step was optimized, and aliquots of up to $100.0 \mu \mathrm{L}$ were injected into the HPLC.

\section{Validation of metformin HCl methods for DBSs}

Full validation of analytical methods for metformin $\mathrm{HCl}$ in DBS was conducted, with the parameters selectivity, carry-over, lower limit of quantitation (LLOQ), linearity of calibration curve, accuracy, precision and recovery, dilution integrity, and stability.

\section{RESULTS AND DISCUSSION}

\section{Optimization of chromatography conditions}

Initially, we optimized detection wavelengths for metformin $\mathrm{HCl}$ and then adjusted the SDS concentration to $10 \mathrm{mM}$ for optimal provision of an ion pair that acts perfectly with metformin HCl. The mobile phase was optimized to maximize peak responses of the combination of acetonitrile phosphate buffer (40:60; pH 7.0). Mixing of the mobile phase was also optimized because it can affect the $\mathrm{pH}$ of the phosphate buffer and influence reactions between metformin $\mathrm{HCl}$ and SDS ion pair [7-11]. The preferred mixing method involved manual mixing by the analyst. Finally, the flow rate was optimized to $0.8 \mathrm{~mL} / \mathrm{min}$.
Metformin $\mathrm{HCl}$ was detected using a PDA detector at $234 \mathrm{~nm}$ after elution from a C-18 column (Waters, SunFire ${ }^{\mathrm{TM}} 5 \mu \mathrm{m} ; 250 \mathrm{~mm} \times 4.6 \mathrm{~mm}$ ) under optimal conditions. These included a mobile phase of acetonitrile phosphate buffer $(\mathrm{pH} 7.0 ; 40: 60)$ at a flow rate of $0.8 \mathrm{~mL} / \mathrm{min}$ and column temperature of $40^{\circ} \mathrm{C}$ using calcium atorvastatin as an internal standard. These analytical conditions produced the best separation parameters, including the largest area values, relatively quick retention times, a tailing factor close to 1 , a resolution (R) of $>2$, the largest theoretical (N) plate, and an HETP value that was close to zero.

\section{System suitability test}

After identifying optimal conditions, system suitability tests were conducted with six injections and retention time, area under the curve, and PAR were obtained with a $\mathrm{CV}$ of $<2.0 \%$. Retention time of metformin is $6.872 \mathrm{~min}$ and retention time of atorvastatin is $7.869 \mathrm{~min}$ (Fig. 1).

\section{Optimization of DBS sample preparation}

Preparation or extraction of metformin $\mathrm{HCl}$ was conducted using the protein precipitation method. The protein precipitation solvents used were the polar solvents methanol and acetonitrile and $60 \%$ methanol gave the highest peak analyte and internal standard responses. This was due to the highly polar nature of metformin $\mathrm{HCl}$, which led to greater solubility in a polar solvent. Further studies with the selected solvent were performed to optimize the amount of solvent volume added, the sonication time, and the evaporation step. The optimum sonication time was $10 \mathrm{~min}$, and longer agitation times caused degradation of the analyte. The evaporation step was then optimized to produce a sharper peak (Fig. 2).

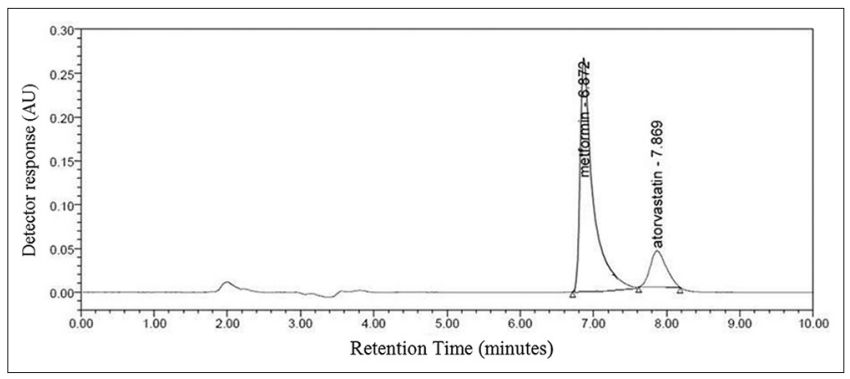

Fig. 1: Chromatogram in system suitability test

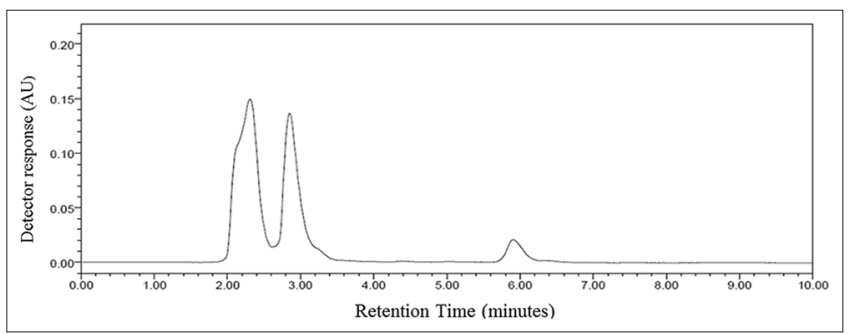

Fig. 2: Chromatogram of dried blood spots extracted blanks

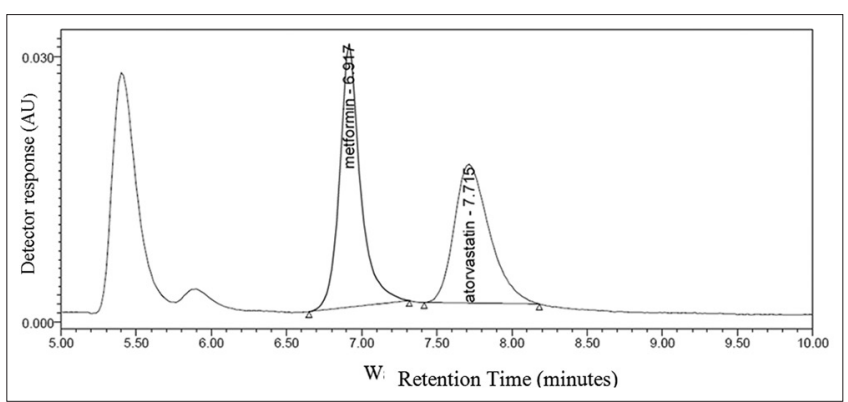

Fig. 3: Chromatogram of metformin $\mathrm{HCl}$ at the upper limit of quantitation concentration of $5000 \mathrm{ng} / \mathrm{Ml}$ 
Validation of metformin $\mathrm{HCl}$ methods in DBSs

\section{Selectivity}

Analyzes of selectivity were performed on blank and LLOQ concentrations using blood from six different sources. The results showed no interference with internal standard or with impurities at the retention time of analyte.

\section{Carry-over}

Carry-over tests showed no carry-over effects in blanks after the highest concentration (upper limit of quantitation) of metformin $\mathrm{HCl}$ was injected (Fig. 3). The carry-over percentage met the requirement $(<20 \%)$ for analytes, as shown in Table 1.

\section{Calibration curve and LLOQ}

The calibration curve was linear and had a correlation coefficient (r) of $>0.999$ in the concentration range of $25.0-5000.0 \mathrm{ng} / \mathrm{mL}$. The concentration of the LLOQ of metformin $\mathrm{HCl}$ was $25.0 \mathrm{ng} / \mathrm{mL}$, with a CV of $10.72 \%$ and a percentage difference of $-14.36 \%-14.10 \%$ (Fig. 4 ).

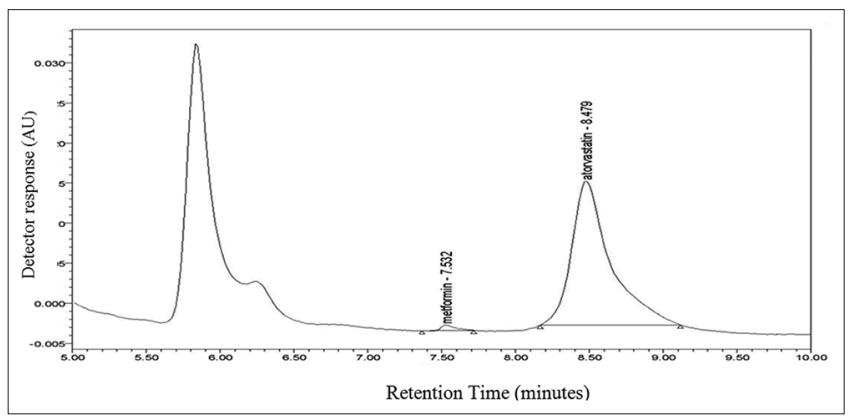

Fig. 4: Chromatogram of metformin $\mathrm{HCl}$ at the lower limit of quantitation concentration of $25.0 \mathrm{ng} / \mathrm{mL}$
Accuracy, precision, and recovery

Estimates of accuracy are based on the proximity of measurements with actual concentrations (bias), whereas those of precision are based on repeatability of determinations (CV). Accuracy and precision tests were conducted within and between runs using concentrations that corresponded with the LLOQ, quality control low (QCL), quality control mid, and quality control high (QCH). Accuracy and precision data from within and between days are shown in Table 2 .

The recovery test was performed by comparing analytical peak responses in DBS with those of standard solution at the same concentrations (Table 3).

\section{Dilution integrity}

Dilution integrity tests were conducted to assess accuracy, precision, and reliability of dilution processes during bioanalysis. If in vivo measurements of metformin $\mathrm{HCl}$ levels in biological matrices exceed the upper limit of $5000 \mathrm{ng} / \mathrm{mL}$, then dilution to within the range of the calibration curve is required. The results of dilution integrity tests are shown in Table 4

\section{Stability}

The stability of metformin $\mathrm{HCl}$ was tested to determine whether degradation occurred during storage. Stability tests were performed by analyzing QCL and QCH samples with three replicates for each sample. In short-term stability tests, samples were stored at room temperature and were stable after 0,6 , and $24 \mathrm{~h}$. The results shown in Table 5 indicate that metformin $\mathrm{HCl}$ samples are stable during storage at room temperature for at least $24 \mathrm{~h}$.

In long-term stability tests, samples were stored at room temperature with desiccants for 7-45 days. These tests showed that metformin

Table 1: Data from carry-over measurements

\begin{tabular}{lll}
\hline Blanks sample & Carry-over metformin HCl (\%) & Carry-over IS (\%) \\
\hline Blank-1 & 8.7795 & 0.0740 \\
Blank-2 & 8.6564 & 0.0871 \\
Blank-3 & 8.1641 & 0.0868 \\
Blank-4 & 9.2923 & 0.0780 \\
Blank-5 & 8.8410 & 0.0901 \\
Average & 8.7467 & 0.0832 \\
\hline
\end{tabular}

Table 2: Accuracy and precision within-run and between-run

\begin{tabular}{|c|c|c|c|c|c|c|}
\hline \multirow{2}{*}{$\begin{array}{l}\text { Actual concentration } \\
(\mathrm{ng} / \mathrm{mL})\end{array}$} & \multicolumn{3}{|l|}{ Within-run } & \multicolumn{3}{|l|}{ Between-run } \\
\hline & $\begin{array}{l}\text { Measured concentration } \\
\text { (Average } \pm \mathrm{SD} ; \mathrm{ng} / \mathrm{mL} \text { ) }\end{array}$ & CV (\%) & Bias (\%) & $\begin{array}{l}\text { Measured concentration } \\
\text { (average } \pm S D ; \mathrm{ng} / \mathrm{mL} \text { ) }\end{array}$ & CV (\%) & Bias (\%) \\
\hline 25.0 & $25.68 \pm 1.88$ & 7.31 & 2.73 & $26.32 \pm 2.52$ & 9.58 & 5.26 \\
\hline 75.0 & $76.49 \pm 0.95$ & 1.24 & 1.99 & $78.92 \pm 3.46$ & 4.38 & 5.22 \\
\hline 2500 & $2520.61 \pm 72.19$ & 2.86 & 0.83 & $2473.21 \pm 78.59$ & 3.18 & -1.07 \\
\hline 3750 & $3885.96 \pm 89.01$ & 2.29 & 3.62 & $3909.65 \pm 119.14$ & 3.05 & 4.26 \\
\hline
\end{tabular}

Table 3: Recovery of metformin $\mathrm{HCl}$

\begin{tabular}{llll}
\hline Actual concentration $(\mathbf{n g} / \mathbf{m L})$ & Amount of replication & Recovery (average \pm SD; $\%)$ & CV (\%) \\
\hline 75.0 & 3 & $77.48 \pm 0.83$ & 1.07 \\
2500 & 3 & $77.22 \pm 0.12$ & 0.16 \\
3750 & 3 & $77.88 \pm 1.21$ & 1.55 \\
\hline
\end{tabular}

Table 4: Dilution integrity test data within and between runs

\begin{tabular}{|c|c|c|c|c|c|c|c|}
\hline \multirow{2}{*}{$\begin{array}{l}\text { Actual concentrations } \\
\text { (ng/mL) }\end{array}$} & \multirow{2}{*}{$\begin{array}{l}\text { Dilution } \\
\text { factor }\end{array}$} & \multicolumn{3}{|l|}{ Within-run } & \multicolumn{3}{|l|}{ Between-run } \\
\hline & & $\begin{array}{l}\text { Measured concentrations } \\
\text { (average } \pm S D ; n g / m L \text { ) }\end{array}$ & CV (\%) & Bias (\%) & $\begin{array}{l}\text { Measured concentrations } \\
\text { (average } \pm S D ; n g / m L \text { ) }\end{array}$ & CV (\%) & Bias (\%) \\
\hline 3750 & $1 / 2$ & $3844.45 \pm 68.81$ & 1.79 & 2.52 & $3838.72 \pm 67.76$ & 1.77 & 2.36 \\
\hline 1875 & $1 / 4$ & $1939.23 \pm 76.26$ & 3.93 & 3.43 & $1940.78 \pm 50.95$ & 2.63 & 3.51 \\
\hline
\end{tabular}


Table 5: Short-term stability of metformin $\mathrm{HCl}$ in DBS at room temperature

\begin{tabular}{|c|c|c|c|c|c|c|}
\hline \multirow[t]{2}{*}{ Hour } & \multicolumn{3}{|l|}{ QCL $75.0 \mathrm{ng} / \mathrm{mL}$} & \multicolumn{3}{|l|}{ QCH 3750 ng/mL } \\
\hline & $\begin{array}{l}\text { Measured concentrations } \\
\text { (average } \pm S D ; n g / m L \text { ) }\end{array}$ & CV (\%) & Bias (\%) & $\begin{array}{l}\text { Measured concentrations } \\
\text { (average } \pm \mathrm{SD} ; \mathrm{ng} / \mathrm{mL} \text { ) }\end{array}$ & CV (\%) & Bias (\%) \\
\hline 0 & $73.82 \pm 1.51$ & 2.05 & -1.58 & $3869.06 \pm 44.50$ & 1.15 & 3.17 \\
\hline 6 & $71.37 \pm 2.00$ & 2.80 & -4.84 & $3829.97 \pm 17.64$ & 0.46 & 2.13 \\
\hline 24 & $74.99 \pm 0.74$ & 0.98 & -0.02 & $3827.45 \pm 4.53$ & 0.12 & 2.06 \\
\hline
\end{tabular}

Table 6: Long-term stability of metformin $\mathrm{HCl}$ in DBS at room temperature

\begin{tabular}{|c|c|c|c|c|c|c|}
\hline \multirow[t]{2}{*}{ Day } & \multicolumn{3}{|l|}{ QCL $75.0 \mathrm{ng} / \mathrm{mL}$} & \multicolumn{3}{|l|}{ QCH 3750 ng/mL } \\
\hline & $\begin{array}{l}\text { Measured concentrations } \\
\text { (average } \pm \mathrm{SD} ; \mathrm{ng} / \mathrm{mL} \text { ) }\end{array}$ & CV (\%) & Bias (\%) & $\begin{array}{l}\text { Measured concentrations } \\
\text { (average } \pm \mathrm{SD} ; \mathrm{ng} / \mathrm{mL} \text { ) }\end{array}$ & CV (\%) & Bias (\%) \\
\hline 0 & $75.40 \pm 1.48$ & 1.96 & 0.53 & $3787.54 \pm 43.52$ & 1.15 & 1.00 \\
\hline 7 & $73.46 \pm 0.34$ & 0.47 & -2.05 & $3776.92 \pm 27.36$ & 0.72 & 0.72 \\
\hline 45 & $71.81 \pm 1.05$ & 1.46 & -4.25 & $3823.65 \pm 33.46$ & 0.88 & 1.96 \\
\hline
\end{tabular}

Table 7: Post-preparation stability (autosampler) of metformin HCl in DBS

\begin{tabular}{|c|c|c|c|c|c|c|}
\hline \multirow[t]{2}{*}{ Hour } & \multicolumn{3}{|l|}{ QCL 75.0 ng/mL } & \multicolumn{3}{|l|}{ QCH 3750 ng/mL } \\
\hline & $\begin{array}{l}\text { Measured concentrations } \\
\text { (average } \pm \mathrm{SD} ; \mathrm{ng} / \mathrm{mL} \text { ) }\end{array}$ & CV (\%) & Bias (\%) & $\begin{array}{l}\text { Measured concentrations } \\
\text { (average } \pm S D ; n g / m L)\end{array}$ & CV (\%) & Bias (\%) \\
\hline 0 & $75.40 \pm 1.48$ & 1.96 & 1.60 & $3787.54 \pm 43.52$ & 1.15 & 1.00 \\
\hline 24 & $72.82 \pm 0.27$ & 0.37 & -2.91 & $3672.88 \pm 17.57$ & 0.48 & 2.05 \\
\hline
\end{tabular}

$\mathrm{HCl}$ samples are stable at room temperature for at least 45 days in the presence of desiccants (Table 6).

To determine the stability of metformin $\mathrm{HCl}$ in the autosampler after preparation of DBS samples, post-preparation stability tests were necessary for $24 \mathrm{~h}$ at the autosampler temperature. As shown in Table 7, $\mathrm{HCl}$ metformin preparations were stable for at least $24 \mathrm{~h}$ in the autosampler.

Short-term stability tests of standard metformin $\mathrm{HCl}$ and internal standard solution were conducted at room temperature for $24 \mathrm{~h}$, and long-term stability tests of standard solution were performed after storage at $-80^{\circ} \mathrm{C}$ for $7-45$ days. The resulting percentage difference for the stability of metformin $\mathrm{HCl}$ stock solution was $-1.95 \%-0.27 \%$ and that for calcium atorvastatin stock solution was - $1.76 \%-0.73 \%$. These data suggest that stock solutions of metformin $\mathrm{HCl}$ and calcium atorvastatin are stable at room temperature for at least $24 \mathrm{~h}$ and at -80 ${ }^{\circ} \mathrm{C}$ for 45 days.

\section{CONCLUSION}

The developed method for determination of metformin $\mathrm{HCl}$ in DBS sample was valid in the range of concentration of $25.0-5000.0 \mathrm{ng} / \mathrm{mL}$ and can be applied to in vivo studies. Moreover, metformin $\mathrm{HCl}$ samples are stable during storage at room temperature for at least $24 \mathrm{~h}$ and stock solutions of metformin $\mathrm{HCl}$ and calcium atorvastatin are stable at room temperature for at least $24 \mathrm{~h}$ and at $-80^{\circ} \mathrm{C}$ for 45 days.

\section{CONFLICTS OF INTEREST}

None declared.

\section{REFERENCES}

1. WHO. Global Report on Diabetes. Geneva: WHO Press; 2016.

2. Aburuz S, Millership J, McElnay J. Dried blood spot liquid chromatography assay for therapeutic drug monitoring of metformin. J Chromatogr B Analyt Technol Biomed Life Sci 2006;832:202-7.

3. Lakshmy R. Analysis of the use of dried blood spot measurements in disease screening. J Diabetes Sci Technol 2008;2:242-3.

4. Brem H, Tomic-Canic M. Cellular and molecular basis of wound healing in diabetes. J Clin Invest 2007;117:1219-22.

5. Michigan State University. Department of Chemistry. Internal Standard; 2016. Available from: https://www.2.chemistry.msu.edu/courses/ cem434/Swain_2015_Excel_Problems/Internal\%20Standard\%20\%20 Standard\%20Āddition\%20.pdf. [Last cited on 2016 Oct 08].

6. EMEA. Guideline on Bioanalytical Method Validation. London: Committee for Medicinal Products for Human Use (CHMP); 2011.

7. David V, Medvedovici A, Albu F. Retention behavior of metformin and related impurities in ion-pairing liquid chromatography. J Liq Chromatogr Relat Technol 2005;28:81-95.

8. Elshaboury SR, Mohamed NA, Ahmed S, Farrag S. An efficient ionpair liquid chromatographic method for the determination of some $\mathrm{H} 2$ receptor antagonists. J Chromatogr Sci 2016;54:419-28.

9. Majidano SA, Khuhawar MY. GC determination of famotidine, ranitidine, cimetidine, and metformin in pharmaceutical preparation and serum using methylglyoxal as derivatizing reagent. Chromatographia 2012;75:1311-7.

10. Kolte BL, Raut BB, Deo AA, Bagool MA, Shinde DB. Simultaneous determination of metformin in its multicomponent dosage forms with glipizide and gliclazide using micellar liquid chromatography. J Liq Chromatogr Relat Technol 2003;26:1117-33.

11. Iwasaki Y, Sawada T, Hatayama K, Ohyagi A, Tsukuda Y, Namekawa K, et al. Separation technique for the determination of highly polar metabolites in biological samples. Metabolites 2012;2:496-515. 